\title{
Effects of Social Support on Faculty Workload and Performance
}

\author{
Rosman Bin Md Yusoff ${ }^{1}$, Anwar Khan ${ }^{2,3}$, Mazen F. Rasheed ${ }^{4}$ \& Alamzeb Aamir ${ }^{5,6}$ \\ ${ }^{1}$ Integrity and Good Governance Research Group, Universiti Teknologi Malaysia, Malaysia \\ ${ }^{2}$ Faculty of Management, Universiti Teknologi, Malaysia \\ ${ }^{3}$ COMSATS Institute of I.T, Attock, Pakistan \\ ${ }^{4}$ College of Business Administration, King Saud University, Saudi Arabia \\ ${ }^{5}$ Faculty of Management, Universiti Teknologi, Malaysia \\ ${ }^{6}$ College of Business Administration, King Saud University, Saudi Arabia \\ Correspondence: Anwar Khan, Faculty of Management, Universiti Teknologi, Malaysia. E-mail: \\ anwar_khan@comsats.edu.pk
}

Received: January 13, 2014 Accepted: May 21, 2014 Online Published: May 27, 2014

doi:10.5539/res.v6n2p95 URL: http://dx.doi.org/10.5539/res.v6n2p95

\begin{abstract}
The current study has examined the interaction between social support and workload for predicting the work related performance of academic staff in Pakistan. A self administered questionnaire was distributed among a sample of 400 academic staff working in the six universities of Pakistan. Data was analyzed through multivariate statistics like Factor Analysis and Multiple Regression Analysis. The results of current study showed that workload was negatively related with the work performance, where social support significantly moderated the negative relationship between workload and performance. The findings of this study have provided new insights on interaction between workload, social support and performance in academia of Pakistan through empirically testing the JD-R theory. This study recommends the proper utilization of personal resources at individual and organizational levels for managing workload and performance related problems in academia of Pakistan.
\end{abstract}

Keywords: faculty workload, social support, work performance, academic staff, academia

\section{Introduction}

The review of existing literature shows that in the last few decades, the issue of faculty workload has received a lot of research attention and it is now considered as a serious concern for higher education institutions around the world (Tight, 2010). In the past university teaching was believed to be a profession with less work demands as the environments of universities provided its employees more academic freedom and less work pressure (Winefield et al., 2003). However recently universities have passed through an age of transition due to consistent global changes, resulting in creation of high performance expectation to be met (Goransson \& Brundenius, 2010). Now academician performs complex work because universities are the only organizations, which focus on dual functions of knowledge generation and transmission through continual teaching and research activities (Houston, Meyer, \& Paewai, 2006). Consequently academicians are subjected to intense workload, which hampers their working performance.

In order to deal with the negative effects of workload, researchers in past have suggested different kinds of resources, which buffer the negative effects of workload; among these resources, social support has been most widely studied for its moderating role in work load-performance interactions (Fawzi, 2004). Despite such wide recognition, only few studies have investigated the effect of social support on work load-performance interactions in academia of Pakistan. For this reason, the current study has examined the moderating role of social support on workload-performance interaction in selected universities of Pakistan. The study of workload and its reducing factors in academia of Pakistan deserve special attention because since the year 2002, a paradigm ship has occurred in Higher Education System of Pakistan. Various improvements were made by Government of Pakistan for meeting the need of ever changing markets, resultantly the performance expectations inside universities also increased, which subjected the academic staff to immense workload. Now the academicians are expected not only to teach diverse courses but also to generate new technological knowledge through research. For this reason, the current study has investigated the problem of workload in academia of 
Pakistan by testing the health impairment and motivation assumptions of Job Demands-Resources (JD-R) theory, in such a way that initially the relationship between faculty workload and performance was checked and later on the moderating effects of social support on faculty workload-performance interaction was examined. The results showed that faculty workload was negatively related with work performance and social support was positively related with work performance and it significantly moderated the negative relationship between faculty workload and performance.

\section{Conceptualizing Faculty Workload and Performance}

Faculty workload is a broad terminology, which encompasses a wide range of meanings. In a simple way faculty workload means duties assigned or completed by faculty member (Meyer, 1998) but in broader sense faculty workload includes performing activities like teaching, research and administrative services (Soliman \& Soliman, 1997). For this reason Meyer (1998) identified three measures, which are used to assess the faculty workload, i.e. Total number of hours spent in teaching; total number of hours spent in research; and total number of hours spent in job related administrative services. On the other side, the work performance of academic staff could be simply defined as the behavior (actions), which are carried out by academicians for attaining certain tasks according to pre determined standards. The outcomes of such behavior is goal achievement (Cai \& Lin, 2006). The academic staff work performance can be broadly divided in to task and contextual performance. The task performance consists of teaching effectively to students through interacting with students for ensuing learning and positive changes in their behavior. On other side the contextual performance consists of occupation morality, dedication to teaching, and cooperation among the academic staff (Cai \& Lin, 2006). These two type are connected with each, however they can be distinguished on the basis of their nature and thus can be studied separately (Stephan \& James, 1994).

The previous research shows that there is complex relationship between workload and performance. Initially it was thought that with increase in workload the performance also increases, but later on it was found that if workload exceeds it's certain limits, then it results in decreased performance. Depending on the nature of workload, variations occur in the level of individual performance in such a way that if the workload includes performing of routine tasks then performance is not affected, however if the task difficulty increases, the level of performance significantly decreases (Oron-Gilad, Szalma, Stafford, \& Hancock, 2008). In other words, if academic staff perform their routine teaching related activities then their performance will not be affected but if they are assigned extra research and service related activities, then it is more likely that their performance level will decrease. It happens because with an increase in task difficulty, the level of resource consumption also increases, which ultimately causes resource depletion and decrease performance (Yeh \& Wickens, 1988).

\section{The Moderating Role of Social Support}

Resources are factors that have either value in their own benefits e.g. close attachment, health and self esteem, or acts as a mean to achieve any required objectives e.g. money, status, and support (Hobfoll, 2002) thus resources possessed by academic staff, buffers the negative effects of workload on performance, where the performance of academic staff is supposed to increase in presence of resources and vice versa. Social support as a personal resource lead individuals to believe that they have been cared, loved and esteemed by others (Cobb, 1976). Individuals may receive social support from work related sources (supervisor, colleagues, subordinates) or non work related sources (friends, family members, relatives) (van Daalen, Sanders, \& Willemsen, 2005). Research on moderating role of social support is inconsistent. Some researchers, e.g. Wells (Wells, 1982), Ng \& Sorensen (Ng \& Sorensen, 2008), Huffman, Watrous-Rodriguez, \& King (Huffman, Watrous-Rodriguez, \& King, 2008) suggested that only work related sources of social support have significant impact, while other researchers, e.g. van Daalen, Sanders, \& Willemsen (van Daalen et al., 2005), Kowalski (Kowalski, 2012), Halbesleben (Halbesleben, 2006) suggested that the combination of both work and non work sources of social have significant effect on employees wellbeing and performance. No matter either social support is received from work or non work source, it has significant moderating effect on negative relationship between workload and performance because during exposure to high workload, the process of resources depletion is stabilized through supply of social support, which balance the rate of resources depletion and thus helps the academic staff to maintain performance standards.

\section{Assumptions of the Current Study}

Although previous research has suggested that social support can buffer the negative effects of workload but no investigations have been carried out to find the moderating role of social support in academia of Pakistan, especially with respect to the recent changes that have occurred in higher education system of Pakistan, which have resulted increase in performance expectations and workloads. The current study, therefore further extends the previous research by testing the Job Demands-Resources (JD-R) theory among academic staff in both public 
and private sector universities of Pakistan. The core of JD-R theory is that every occupation has two risk factors, i.e. Job demands and resources. The job demands set off health impairment process while resources trigger motivational process (Bakker \& Demerout, 2013). Keeping in view these two processes, the current study assumes that workload as job demand affect performance of academic staff, while social support as personal resource moderates the negative relationship between workload and performance. More specifically the current study will test the following hypotheses:

Hypothesis 01: Faculty workload will be the predictor of work performance, where faculty workload will be negatively related with work performance.

Hypothesis 02: Social support will be the predictor of work performance, where it will moderate the negative relationship between faculty workload and work performance.

\section{Methods}

\subsection{Population and Sample}

The current study has used a multi stage sampling process. Initially, three geographical regions of Pakistan, i.e. North Punjab, Federal Area Islamabad and Central Khyber Pakhtunkhwa were selected as clusters. These clusters represented the total population of study. Only three regions were selected because it was not physically possible to collect data from whole Pakistan. Table 1 shows the detail of selected universities.

Table 1. Universities selected universities

\begin{tabular}{lcc}
\hline Regions & No of Universities & No of Academic staff \\
\hline Federal Area Islamabad & 16 & 2300 \\
North Punjab & 07 & 675 \\
Central Khyber Pakhtunkhwa & 13 & 1770 \\
Total & $\mathbf{3 6}$ & $\mathbf{4 7 4 5}$ \\
\hline
\end{tabular}

Due to large number of universities in these clusters, only six universities were randomly selected. It was ensured that both public and private universities are equally selected; moreover universities with more number of academic staff were selected because they could give better representation of total population. The Table 2 shows the detail.

Table 2. Randomly selected universities

\begin{tabular}{|c|c|c|c|}
\hline Universities/HEIs & Nature & Type & No of Staff \\
\hline \multicolumn{4}{|l|}{ Federal Area Islamabad } \\
\hline 1. International Islamic University, Islamabad & General \& Islamic studies & Public & 263 \\
\hline 2. Riphah International & General \& Medical & Private & 265 \\
\hline \multicolumn{4}{|l|}{ North Punjab } \\
\hline 3. UET, Taxila & Engineering & Public & 173 \\
\hline 4. University of Wah, Wah & General* & Private & 115 \\
\hline \multicolumn{4}{|l|}{ Central Khyber Pakhtunkhwa } \\
\hline 5. University of Peshawar, Peshawar & General & Public & 251 \\
\hline 6. SUIT, Peshawar & Science \& Technology & Private & 190 \\
\hline Total 1257 & & & \\
\hline
\end{tabular}

In the last stage a sample of $600(69+107+177+247=600)$ was obtained from the total population of 1257 . This sample was obtained by firstly dividing population into male and female strata. Such strata were further divided into Professor, Associate Professor, Assistant Professor and Lecturer. After stratification, finally a simple random sample of 600 was obtained, as the number of academic staff was already known and they had also equal likelihood of being chosen. Table 3 shows the population and sample distributions. 
Table 3. Population and sample description

\begin{tabular}{|c|c|c|c|c|c|c|c|c|}
\hline Universities/HEIs & $\begin{array}{l}\text { Prof } \\
(\mathbf{N})\end{array}$ & $\begin{array}{c}\text { Prof } \\
(n)\end{array}$ & $\begin{array}{l}\text { Asso Prof } \\
(\mathbf{N})\end{array}$ & $\begin{array}{l}\text { Asso Prof } \\
\text { (n) }\end{array}$ & $\begin{array}{c}\text { Asst } \\
\text { Prof (N) } \\
\end{array}$ & $\begin{array}{c}\text { Asst } \\
\text { Prof (n) }\end{array}$ & $\begin{array}{l}\text { Lec } \\
(\mathrm{N})\end{array}$ & $\begin{array}{l}\text { Lec } \\
(n)\end{array}$ \\
\hline $\begin{array}{l}\text { Riphah } \\
\text { Islamabad }\end{array}$ & 35 & 22 & 28 & 10 & 89 & 36 & 113 & 46 \\
\hline International & & & & & & & & \\
\hline University & 22 & 12 & 42 & 30 & 93 & 37 & 106 & 43 \\
\hline University of Wah & 08 & 05 & 13 & 06 & 38 & 20 & 56 & 36 \\
\hline UET, Taxila & 28 & 10 & 38 & 25 & 63 & 26 & 44 & 30 \\
\hline Peshawar University & 32 & 15 & 44 & 29 & 48 & 30 & 127 & 51 \\
\hline SUIT, Peshawar & 09 & 05 & 17 & 07 & 62 & 28 & 102 & 41 \\
\hline Total & 134 & 69 & 182 & 107 & 393 & 177 & 548 & 247 \\
\hline
\end{tabular}

\subsection{Scale Selection}

The following scales were used for data collection:

\subsubsection{Demographics}

The respondents were asked to provide information regarding their gender, age, marital status, job position and job experience.

\subsubsection{Faculty Workload}

Faculty Workload was assessed by using 10 items of Gmelch, Wilke, \& Lovrich's (1986) Faculty Stress Index. In this regard, 03 items were assigned to teaching load dimension; 03 items to research load and 04 items to administrative load.

\subsubsection{Social Support}

Social Support was divided in to support from colleagues, supervisor and organization. The social support from colleagues was assessed by 04 items of Iverson, Olekalns, \& Erwin's (Iverson, Olekalns, \& Erwin, 1998) Social Support Scale. Whereas, the social support from organization was assessed by 04 items of Eisenberger, et al., (Eisenberger, Huntington, Huntchison, \& Sowa, 1986) Organizational Support Scale

\subsubsection{Work Performance}

The Work Performance was measured by 10 items, where 05 items were taken from Goodman \& Svyantek's (1999) Scale and 05 items from Williams \& Anderson's (1991) Scale.

Items related to demographic data were assigned nominal scale, whereas items of Faculty Workload, Social Support and Work Performance were assigned five point Likert type of scale, i.e. (01 strongly disagree to 05 strongly agree).

\subsection{Data Collection Procedure}

The data was collected through distribution of printed questionnaires among faculty members in the selected universities. Within a period of six months total 486 questionnaires were filled and returned back by the respondents. The filled questionnaires were initially screened for missing data and later on the normality analyses were performed on it. Finally total 400 usable questionnaires were selected for further analysis.

\subsection{Statistical Analysis}

Data was analyzed by using Confirmatory Factor Analysis and Multiple Regression Analysis. The Confirmatory Factor Analysis was performed to determine the overall construct validity of the selected scales, whereas Hierarchical Multiple Regression Analysis was performed for testing the hypotheses. In this regard separate models were built for testing each hypothesis. The data was entered into model in three successive steps. In the first step, the demographic data was entered as control variables. In the second step, the independent variables of Workload and Social Support were entered into the model and in the last step, the interaction term, i.e. Social Support x Workload was added into the model. Standardized z-scores for all variables were computed in order to avoid any Multicollinearity related problems.

\section{Results}

\subsection{Confirmatory Factor Analysis}

The results of Confirmatory Factor Analysis showed that all scales possessed construct validities. The standardized factor loadings for items of all variables ranged from 0.60 to 0.80 . Similarly, the correlations 
between items of all variable ranged from 0.40 to 0.60 . On other side, the model fit indices were also within acceptable ranges, as clear from table 4. For the variable of workload, three factors model, i.e. (teaching, research and administrative work) was adopted, whereas for the variable of work performance two factors model, i.e. (task and contextual performance) was selected. Similarly for the social support two factor models, i.e. (support from colleagues and support from organization) was selected.

Table 4. Results of confirmatory factor analysis

\begin{tabular}{lllllllll}
\hline Variables & Models & $\boldsymbol{X}^{2}$ & $\boldsymbol{d} \boldsymbol{f}$ & $\boldsymbol{X}^{2} / \boldsymbol{d} \boldsymbol{f}$ & $\mathbf{R M R}$ & $\mathbf{C F I}$ & GFI & RMSEA \\
\hline Workload & Three factors model & 59.4 & 32 & 1.86 & 0.030 & 0.99 & 0.98 & 0.044 \\
Work Performance & Two factors model & 64.0 & 30 & 2.13 & 0.011 & 0.99 & 0.98 & 0.051 \\
Social Support & Two factors model & 18.9 & 11 & 1.72 & 0.009 & 0.99 & 0.99 & 0.041 \\
\hline
\end{tabular}

\subsection{Regression Analysis}

The results of Hierarchical Multiple Regression Analysis showed that the demographic variables in first step explained a negligible amount of variance in work performance, therefore it could be ignored, however, in the second step, the independent variable of faculty workload explained $20 \%$ of variance in work performance, which was significant at $p<0.05$ level, with F-test value of 39.851 as clear from table 5 . The details of analysis showed that standardized $\beta$ Coefficients for three types of workload were significant and negative. Thus the first hypothesis was accepted.

Table 5. Regression analysis results (Hypothesis 01)

\begin{tabular}{lcc}
\hline & \multicolumn{2}{c}{ Work Performance $^{\mathrm{a}}$} \\
\hline Step 01 & $\boldsymbol{\beta}^{\mathrm{b}}$ & $\mathbf{t}^{\mathrm{c}}$ \\
Gender & 0.002 & 0.038 \\
Age & 0.120 & 0.596 \\
Marital Status & -0.047 & -0.842 \\
Job Position & 0.037 & 0.157 \\
Experience & 0.012 & 0.075 \\
Step 02 & & \\
Gender & -0.024 & -0.568 \\
Age & -0.081 & -0.442 \\
Marital Status & -0.045 & -0.904 \\
Job Position & 0.102 & 0.482 \\
Experience & 0.103 & 0.736 \\
Workload (teaching activities) & $-0.136^{*}$ & -2.907 \\
Workload (research activities) & $-0.222^{* *}$ & -4.000 \\
Workload (administrative activities) & $-0.201^{* *}$ & -3.883 \\
$\Delta \mathrm{R}^{2}$ Step 01 & $0.038^{*}$ & \\
$\Delta \mathrm{R}^{2}$ Step 02 & $0.193^{* *}$ & \\
$\Delta \mathrm{F}$ Step 01 & $3.405^{*}$ & \\
$\Delta \mathrm{F}$ Step 02 & $35.347^{* *}$ & \\
\hline Note a Depend & & \\
\hline
\end{tabular}

Note: $\mathbf{a}=$ Dependent Variable; $\mathbf{b}=$ Standardized $\beta$ Coefficients reported; $\mathbf{c}=\mathrm{t}$-test scores; ${ }^{*}$ Significant at $\mathbf{p}<0.05$; ** Significant at $\mathrm{p}<0.001$

The results of Hierarchical Multiple Moderated Regression Analysis showed that in the demographic variables in all three steps explained a negligible amount of variance in work performance, therefore it could be ignored. In the second step, the three types of workload and two types of social support collectively explained a mean variance of $43 \%$ in work performance variable, which was significant at $p<0.001$, with mean F-test value of 124.93. In the third step, the interaction term, i.e. Social Support $x$ Workload explained a mean variance of $19 \%$ in work performance variable, which was significant at $\mathrm{p}<0.05$, with mean F-test value of 115.10 , where social support from colleagues significantly moderated the relationship between teaching load, research load, administrative load and work performance. The social support from organization only moderated the relationship 
between administrative load and work performance. It means that social support acts as moderator in workload-performance interaction. Therefore, the second hypothesis was also accepted.

Table 6. Moderated Regression Analysis results

\begin{tabular}{|c|c|c|c|}
\hline & \multicolumn{3}{|c|}{ Job Performance $^{\mathrm{a}}$} \\
\hline Step 01 & $\beta^{b}$ & $\beta$ & $\beta$ \\
\hline Gender & 0.002 & 0.002 & 0.002 \\
\hline Age & 0.120 & 0.120 & 0.120 \\
\hline Marital Status & -0.047 & -0.047 & -0.047 \\
\hline Job Position & 0.037 & 0.037 & 0.037 \\
\hline Experience & 0.012 & 0.012 & 0.012 \\
\hline \multicolumn{4}{|l|}{ Step 02} \\
\hline Gender & -0.061 & -0.058 & -0.063 \\
\hline Age & -0.143 & -0.184 & -0.226 \\
\hline Marital Status & -0.049 & -0.046 & -0.054 \\
\hline Job Position & 0.246 & 0.247 & 0.249 \\
\hline Experience & -0.048 & -0.003 & 0.035 \\
\hline Workload (teaching activities) & $-0.144 * *$ & --- & -- \\
\hline Workload (research activities) & --- & $-0.218 * *$ & -- \\
\hline Workload (administrative activities) & --- & --- & $-0.235^{* *}$ \\
\hline Social Support (colleagues) & $0.379^{* *}$ & $0.375^{* *}$ & $0.391 * *$ \\
\hline Social Support (organization) & $0.343^{* *}$ & $0.303^{* *}$ & $0.309^{* *}$ \\
\hline \multicolumn{4}{|l|}{ Step 03} \\
\hline Gender & -0.060 & -0.054 & -0.057 \\
\hline Age & -0.161 & -0.193 & -0.229 \\
\hline Marital Status & -0.048 & -0.044 & -0.051 \\
\hline Job Position & 0.265 & 0.262 & 0.269 \\
\hline Experience & -0.040 & -0.003 & 0.023 \\
\hline Workload (teaching activities) & $-0.103 *$ & --- & \\
\hline Workload (research activities) & --- & $-0.177 * *$ & \\
\hline Workload (administrative activities) & --- & --- & $-0.186^{* *}$ \\
\hline Social Support (colleagues) & $0.378^{* *}$ & $0.380 * *$ & $0.404 * *$ \\
\hline Social Support (organization) & $0.354^{* *}$ & $0.311^{* *}$ & $0.316^{* *}$ \\
\hline WLTA x SSC & $0.149^{*}$ & --- & --- \\
\hline WLTA x SSO & 0.050 & --- & --- \\
\hline WLRA x SSC & --- & $0.189^{*}$ & --- \\
\hline WLRA x SSO & --- & 0.013 & --- \\
\hline WLAA x SSC & --- & --- & $0.177^{*}$ \\
\hline WLAA x SSO & --- & --- & $0.126^{*}$ \\
\hline$\Delta \mathrm{R} \& \Delta \mathrm{F}$ Step 01 & $0.032 \& 3.40$ & $0.038 \& 3.40$ & $0.038 \& 3.40$ \\
\hline$\Delta \mathrm{R} \& \Delta \mathrm{F}$ Step 02 & $0.42 \& 115.4$ & $0.45 \& 127.2$ & $0.46 \& 132.2$ \\
\hline$\Delta \mathrm{R} \& \Delta \mathrm{F}$ Step 03 & $0.25 \& 122.5$ & $0.15 \& 112.2$ & $0.16 \& 110.6$ \\
\hline
\end{tabular}

Note: $\mathbf{a}=$ Dependent Variable; $\mathbf{b}=$ Standardized $\beta$ Coefficients reported; WLTA $=$ Workload $($ Teaching Activities); WLRA=Workload (Research Activities); WLAA= Workload (Administrative Activities); $\mathbf{S S C}=$ Social Support (colleagues); SSO $=$ Social Support (organization); ${ }^{*}$ Significant at $\mathrm{p}<0.05$; $* *$ Significant at $\mathrm{p}<0.001$

\section{Discussion on Findings}

The current study investigated the problem of faculty workload in academia of Pakistan by proposing that faculty workload will be negatively related with the work performance of academic staff and the relationship between faculty workload and work performance will be moderated by social support. Following the data analysis, it was found that faculty workload was negatively related with the work performance of academic staff and social support has significantly moderated the relationship between faculty workload and work performance. The results of the current study are consistent with the previous research on faculty workload and its interaction 
with social support and work performance. In past such relationship was extensively studied because the issue of workload and poor performance was a real concern for both academicians and researchers. Resultantly, they were in search of different solutions to uphold the performance of academic staff, which is suffering from negative effects of workload. Among the previous studies, Kyriacou (1981) was pioneers to study the moderating effect of resources (Social Support) in teaching profession. Later on different research studies were conducted on the moderating effect of social support, e.g. Gillespie, Walsh, Winefield, Dua, \& Stough (2001) conducted a study on the perception, causes and consiqueces of occupational stress in Australian univeristies and found that Social Support had significant moderating effect on occupational stressors like work overload, job insecurity, and lack of promotion. Similarly, Chan (2002) conducted study on causes and consequences of job stress among Chinese teachers in Hong Kong and found that social support significantly moderated the negative effects of workload. Recently Sun, Wu, \& Wang (2011) and Moeller \& Chung-Yan (Moeller \& Chung-Yan, 2013) have found social support as potential moderator of workload. The findings of previous studies prove that social support could be used to buffer the negative effects of workload on faculty's performance, wellbeing and health. It is therefore suggested that academic institutions in Pakistan should provide sufficient amount of social support to their faculty members, so that they can better manage their workload and work performance.

\section{Theoretical and Empirical Contributions}

The current study has made certain theoretical and empirical contributions. Theoretically, it has successfully validated the JD-R theory by testing its health impairment and motivational processes among a large sample of 400 respondents working in six universities of Pakistan. The findings of current study showed that during the health impairment process, workload was negatively related with the work performance of academic staff, whereas in the motivational process, social support significantly moderated the negative relationship between workload and performance. The successful validation of the two core processes of JD-R theory is proof of its stability.

The findings of current study have also certain practical implications. At individual level, it is suggested that academic staff should get awareness about possible sources and consequences of workload; furthermore, they should get awareness about different sources of social support. In this manner they can ultimately develop coping capacities for managing workload and performance related issues. At managerial level, the universities should provide a conducive work environment, which is free from work related stressors with abundant amount of personal and job related resources. It is also strongly advised that the universities should launch stress management training programs, so that academic staff gets awareness about the problem of work stress. At policy level, the high education ministry should formulate policies related to better workplace design and working conditions. In this regard, a proper legislation should be made, which address all issues related to workplace setting. Furthermore, the budget of universities should also be increased so that there are enough available resources to the academic staff and within universities.

\section{Limitations and Future Recommendations}

The current study has following limitations and future recommendations:

1. The current study has reported subjective data. It is recommended that the future researcher should collect both subjective and objective data. It will be helpful in getting more precise results.

2. The current study has only investigated the relationship of workload, social support and work performance. It is recommended that future studies should include other types of work demands and resources for knowing their interaction with the work performance.

3. The current study was cross sectional in nature. It is recommended that future research studies should also be carried out on longitudinal basis. It will be helpful in knowing the changing patterns of employees' workload and performance perceptions with the passage of time.

4. The current study has conducted main effect and moderation effect analysis. It is recommended that future researchers should conduct studies on reversed causation and reciprocity analysis. It will be helpful in knowing causal basis of faculty workload and performance relationship.

\section{References}

Bakker, A., \& Demerout, E. (2013). Job Demands-Resources Theory. In Cooper (Ed.), Wellbeing: A Complete Reference Guide. Chichester: John Wiley \& Sons, Limited.

Cai, Y., \& Lin, C. (2006). Theory and Practice on Teacher Performance Evaluation. Frontiers of Education in China, 1(1), 29-39. http://dx.doi.org/10.1007/s11516-005-0004-x 
Chan, D. (2002). Stress, Self-Efficacy, Social Support, and Psychological Distress among Prospective Chinese Teachers in Hong Kong. Educational Psychology, 22(5), 557-569. http://dx.doi.org/10.1080 /0144341022000023635

Cobb, S. (1976). Social support as a moderator of life stress. Psychosomatic medicine, 38(5), 300-314. http://dx.doi.org/10.1097/00006842-197609000-00003

Eisenberger, R., Huntington, R., Huntchison, S., \& Sowa, D. (1986). Perceived Organisational Support. Journal of Applied Psychology, 71(3), 500-507. http://dx.doi.org/10.1037/0021-9010.71.3.500

Fawzi, A. (2004). Job Stress, Job Performance, and Social Support among Hospital Nurses. Journal of Nursing Scholarship, 36(1), 73-78. http://dx.doi.org/10.1111/j.1547-5069.2004.04016.x

Gillespie, N. A., Walsh, M., Winefield, A. H., Dua J., \& Stough, C. (2001). Occupational stress in universities: Staff perceptions of the causes, consequences and moderators of stress. Work \& Stress, 15(1), 53-72. http://dx.doi.org/10.1080/02678370117944

Gmelch, W., Wilke, P. K., \& Lovrich Jr, N. (1986). Dimensions of stress among university faculty: Factor-analytic results from a national study. Research in Higher Education, 24(3), 266-286. http://dx.doi.org/10.1007/BF00992075

Goodman, S., \& Svyantek, D. (1999). Person-organization fit and contextual performance: Do shared values matter. Journal of Vocational Behavior, 55(2), 254-275. http://dx.doi.org/10.1006/jvbe.1998.1682

Goransson, B., \& Brundenius, C. (2010). Background and Introductaion. In B. Göransson, \& C. Brundenius (Eds.), Universities in Transition: The Changing Role and Challenges for Academic Institutions (pp. 3-10). Springer.

Halbesleben, J. (2006). Sources of social support and burnout: a meta-analytic test of the conservation of resources model. Journal of applied Psychology, 91(5), 1134. http://dx.doi.org/10.1037/0021 $-9010.91 .5 .1134$

Hobfoll, S. E. (2002). Social and Psychological Resources and Adaptation. Review of General Psychology, 6(4), 307-324. http://dx.doi.org/10.1037/1089-2680.6.4.307

Houston, D., Meyer, L., \& Paewai, S. (2006). Academic Staff Workloads and Job Satisfaction: Expectations and values in academe. Journal of Higher Education Policy and Management, 28(1), 17-30. http://dx.doi.org $/ 10.1080 / 13600800500283734$

Huffman, A., Watrous-Rodriguez, K., \& King, E. (2008). Supporting a diverse workforce: What type of support is most meaningful for lesbian and gay employees? Human Resource Management, 47(2), 237-253. http://dx.doi.org/10.1002/hrm.20210

Iverson, R. D., Olekalns, M., \& Erwin, P. J. (1998). Affectivity, Organizational Stressors, and Absenteeism: A Causal Model of Burnout and Its Consequences. Journal of Vocational Behavior, 52(1), 1-23. http://dx.doi.org/10.1006/jvbe.1996.1556

Kowalski, T. (2012). Exploring the Contribution of Work and Non-Work Sources of Social Support to Employee Well-being. Paper presented at the Conference of European Academy of Occupational Health Psychology Zurich, United Kingdom.

Kyriacou, C. (1981). Social Support and Occupational Stress among Schoolteachers. Educational Studies, 7(1), 55-60. http://dx.doi.org/10.1080/0305569810070108

Meyer, K. A. (1998). Faculty workload studies: perspectives, needs, and future directions (Vol. 26). Graduate School of Education and Human Development, George Washington University.

Moeller, C., \& Chung-Yan, G. (2013). Effects of social support on professors' work stress. International Journal of Educational Management, 27(3), 188-202. http://dx.doi.org/10.1108/09513541311306431

Ng, T., \& Sorensen, K. (2008). Toward a Further Understanding of the Relationships Between Perceptions of Support and Work Attitudes A Meta-Analysis. Group \& Organization Management, 33(3), 243-268. http://dx.doi.org/10.1177/1059601107313307

Oron-Gilad, T., Szalma, J., Stafford, S., \& Hancock, P. (2008). The workload and performance relationship in the real world: A study of police officers in a field shooting exercise. International Journal of Occupational Safety and Ergonomics, 14(2), 119-131. 
Soliman, I., \& Soliman, H. (1997). Academic workload and quality. Assessment \& Evaluation in Higher Education, 22(2), 135-157. http://dx.doi.org/10.1080/0260293970220204

Stephan, M., \& James, V. S. (1994). Evidence that task performance should be distinguished from contextual performance. Journal of Applied Psychology, 79(4), 475-480. http://dx.doi.org/10.1037/0021-9010.79.4.475

Sun, W., Wu, H., \& Wang, L. (2011). Occupational Stress and Its Related Factors among University Teachers in China. Journal of occupational health, 53(4), 280-286. http://dx.doi.org/10.1539/joh.10-0058-OA

Tight, M. (2010). Are Academic Workloads Increasing? The Post-War Survey Evidence in the UK. Higher Education Quarterly, 64(2), 200-215. http://dx.doi.org/10.1111/j.1468-2273.2009.00433.x

van Daalen, G., Sanders, K., \& Willemsen, T. (2005). Sources of social support as predictors of health, psychological well-being and life satisfaction among Dutch male and female dual-earners. Women \& Health, 41(2), 43-62. http://dx.doi.org/10.1300/J013v41n02_04

Wells, J. (1982). Objective job conditions, social support and perceived stress among blue collar workers. Journal of Organizational Behavior, 3(1), 79-94. http://dx.doi.org/10.1002/job.4030030107

Williams, L., \& Anderson, S. (1991). Job satisfaction and organizational commitment as predictors of organizational citizenship and in-role behaviors. Journal of Management, 17(3), 601-617. http://dx.doi.org $/ 10.1177 / 014920639101700305$

Winefield, Gillespie, N., Stough, C., Dua, J., Hapuarachchi, J., \& Boyd, C. (2003). Occupational stress in Australian university staff: Results from a national survey. International Journal of Stress Management, 10(1), 51-63. http://dx.doi.org/10.1037/1072-5245.10.1.51

Yeh, Y.-Y., \& Wickens, C. (1988). Dissociation of Performance and Subjective Measures of Workload. Human Factors: The Journal of the Human Factors and Ergonomics Society, 30(1), 111-120.

\section{Copyrights}

Copyright for this article is retained by the author(s), with first publication rights granted to the journal.

This is an open-access article distributed under the terms and conditions of the Creative Commons Attribution license (http://creativecommons.org/licenses/by/3.0/). 